\title{
A Comparative Study of Preschool Teachers' Instruction Method in Concrete Cases between Japan and China: Application of Personal Teaching Theory
}

\author{
Linqi Chen \\ Graduate School of Education \\ Hiroshima University \\ Kagamiyama, Higashi-hiroshima \\ Hiroshima 739-8524 \\ Japan \\ Atsushi Nanakida \\ Hiroshima University \\ Kagamiyama, Higashi-hiroshima \\ Hiroshima 739-8524 \\ Japan
}

\begin{abstract}
The purpose of this study was to investigate the influence of 'Personal Teaching Theory' on preschool teachers. 'Personal Teaching Theory' is a personal belief system on how to treat children according to their aptitudes. A factor analysis based on the data obtained from 108 Japanese and 226 Chinese preschool teachers, the results showed that there were three patterns of instruction methods whether in China or Japan. Among the three patterns, two were the same for both China and Japan. One was "Promote understanding". The other was "Watching over". Regarding the third pattern of Japan, it was called "Assist playing", whereas concerning China, it was "Rectify act". Also, dealing with problem children who are quite aggressive, as the years of preschool teacher experience grow, Japanese preschool teachers chose a flexible intervention which combined "Promote understanding" with "Assist playing" depending on the circumstance. However, Chinese preschool teachers tend to use "Rectify act" more instead of the pattern of "Promote understanding".
\end{abstract}

Keywords: preschool teacher, personal teaching theory, problem children, instruction, Japan, China

\section{Literature review}

Recently, comparative researches of preschool teachers' method of instruction between Japan and China have been conducted prevalently on the early childhood education (Dong, 2009; Yang, 2012). It is an important research theme in enhancing mutual ability of childcare practices (Liu, 2008).Up to now, among the Japanese-Chinese comparative studies on the instruction methods of preschool teachers, most of them have analyzed the characteristics of each other's instruction methods by comparing the differences between Japanese and Chinese preschool teachers' instruction on the same case.

For example, Tobin, Wu and Davidson's "Preschool in Three Cultures" is well-known in this field. In their research, they applied the method that by showing a video of the fight between the children recorded in childcare centers to the preschool teachers and asked about their choice of instruction methods. They found out that Japanese preschool teachers chose to wait for the child who fought with the other to recognize his mistake while in Chinese preschool teachers' belief that Japanese preschool teachers did not fulfill their childcare responsibilities (Tobin, Wu \& Davidson, 1989). Moreover, 20 years later,

Tobin and some new researchers were aiming to determine how globalization and widespread social changes have affected the way children are nurtured in different countries. So, they researched the same preschools again. However, it has been found out that Japanese preschool teachers had not changed their way in dealing with the fight between the children, and nonetheless they often took the watching over method, while Chinese preschool teachers employed intervention more often (Tobin and Hsueh, 2011). 
Also, Liu and Kuramachi (2008) discussed about the differences in the characteristics of Japanese and Chinese intervention in altercation between children. In the research, qualitative research method was used which was the same as Tobin et al. The result showed the characteristic of interventions used by Japanese preschool teachers was that they would let the children think about solutions, while concerning Chinese preschool teachers, only the children who caused the altercation were instructed.

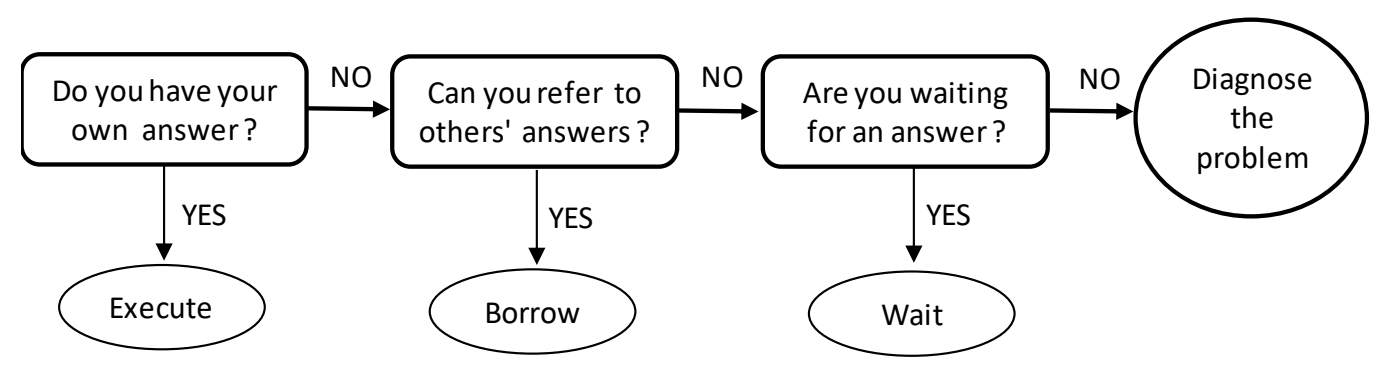

Figure 1 The flowchart of “Problem solving behavior"

However, the following two issues can be pointed out from the above previous studies. First, the link between the instruction method and the case is not discussed. Secondly, the relationship between instruction and preschool teaching experience was not expounded. According to 'Personal Teaching Theory' (hereinafter called PTT), the same preschool teacher may have different methods for different cases, and the instruction methods may also vary depending on the amount of childcare experience.

The PTT, simply speaking, is that every preschool teacher has his or her own beliefs when instructing young children. Specifically speaking, in childcare education, instructing is 'Problem solving behavior'. 'Problem solving behavior' can be divided into three forms. The first type, the preschool teacher has his or her own answer and implements it directly. The second one, although he or she doesn't have the answer, he or she can borrow it from someone else and then implement it. The third type, he or she would wait for the answer to come out on its own. If none of these three forms solves the problem, the preschool teacher will re-examine the problem (Figure 1). What kind of "Problem solving behavior" form the preschool teacher will choose when confronting problems /case depends on the teacher's viewpoint of the problems/case, and this viewpoint may change with the increase of the teaching experience (Kajita,1986).

Based on what has been stated above, the purpose of this study is to investigate Personal Teaching Theory's influence on Japanese and Chinese preschool teachers. Moreover, dealing with problem children, which method of instruction they prefer to choose will be explicated.

\section{Research method}

\subsection{Survey respondents and periods}

The survey was conducted in a number of kindergartens and childcare centers in multiple prefectures in both countries with 108 Japanese and 226 Chinese preschool teachers.

The survey period in Japan was from March to April 201X and in China was from April to May 201X. In Japan, we collected 108 surveys back with 106 valid responses (51 people under 5 years of experience, 55 people over 6 years) (return rate 100\%, effective response rate 98.1\%). The survey in China had 226 collections with 218 valid responses (162 people under 5 years of experience, 56 people over 6 years) (return rate $100 \%$, valid response rate $96.4 \%)$.

\subsection{Survey contents}

The questionnaire consisted of three cases of problem children, which were described in about 100 words attached with three caricatures. The three cases of problem children were case 1 of 5 years old boy who was pretty 
aggressive (Kajita et al., 1988), case 2 of 5 years old girl who was capricious (Tomosada, 2009), and case 3 of 5 years old boy who was easy to cry (Kanamori, 2017). For items related to how to deal with each case, the study of Kajita et al. (1988) was referred. The survey subjects were asked to read the three cases and how they would instruct in each case. In order to convey the image of each case in an easy-to-understand manner, an illustration depicting the characteristics of each case was attached to the survey. A description and illustrations of each case are shown in Figure 2below.

The reason for setting the age of all children in each case to 5 years is that if the problem child is 5 years old, the preschool teachers' instruction method will be diverse (Shiraishi \& Tomosada, 2007).

\subsection{Analysis}

In order to clarify the level of motivation for preschool teachers to apply each instruction method, they were asked to select from four levels: "1 very applicable", "2 somewhat applicable", "3 not applicable", and "4 not applicable at all" for each item. 4 points for those who answered " 1 very applicable", 3 points for those who answered " 2 somewhat applicable", 2 points for those who answered " 3 not so applicable", 1 point for those who answered "4 not applicable at all"; thus to calculate the score of each item.

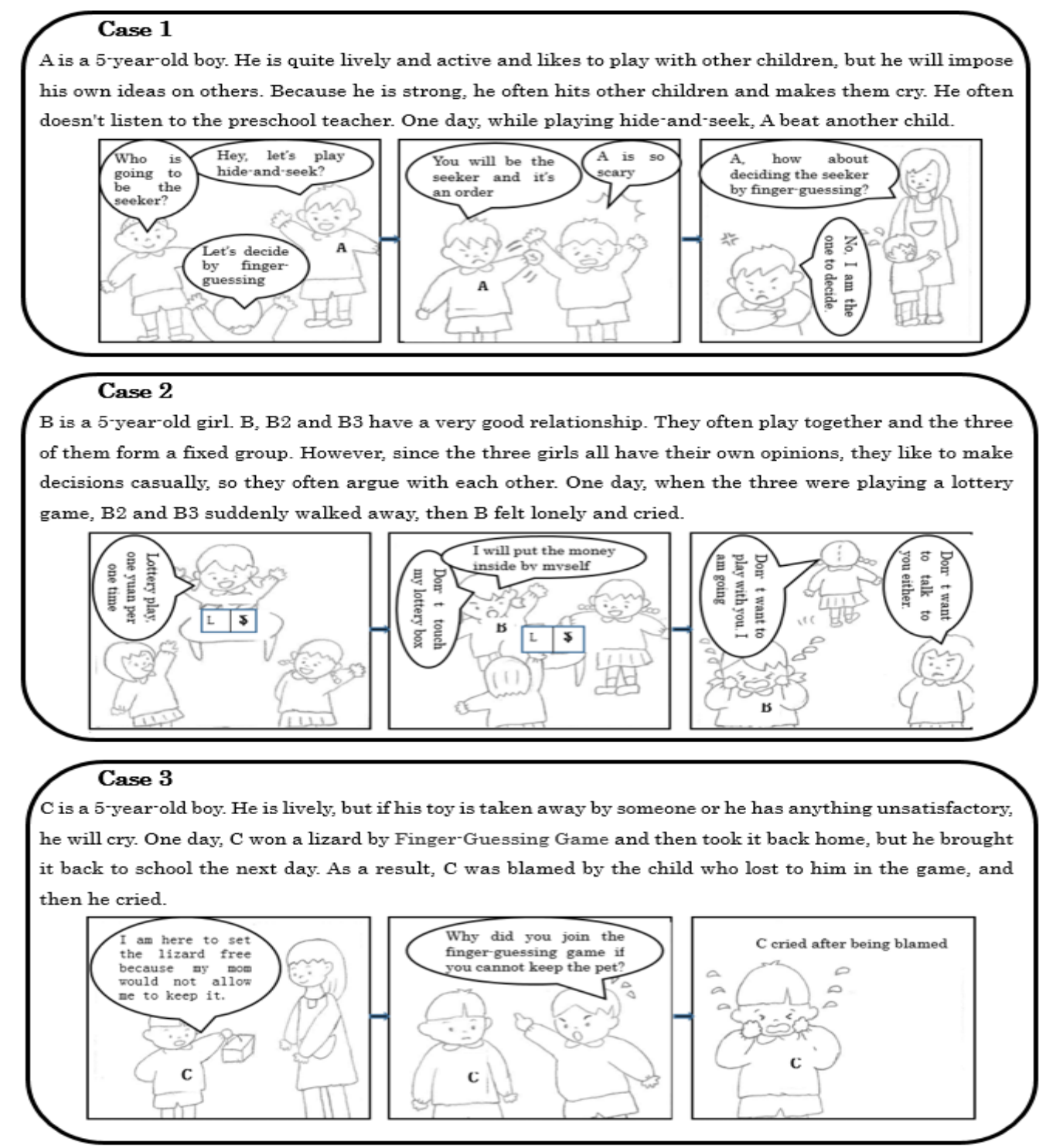

Figure 2 A description and illustrations of each case

\subsection{Overall trend of instruction method}


In this section, from the 35 instruction methods, we will conduct Japan-China comparison by using the averages obtained from different cases and different teaching experience. In table 1, the symbolO means in specific case and preschool teaching experience, this item's average score is higher than 2.8. The symbol $\square$ means in specific cases only, the average of this item is higher than 2.8 (the average score is divided into 5 scales, 1.0 1.6, 1.6 2.2, $2.2 \sim 2.8,2.8 \sim 3.4,3.4 \sim 4.0$. When the average score is higher than 2.8 , it shows the item is a common instruction method.) (Kajita et al, 1988).

Table 1 Items with an average value of 2.8 or higher

(The $O$ are 2.8 or higher)

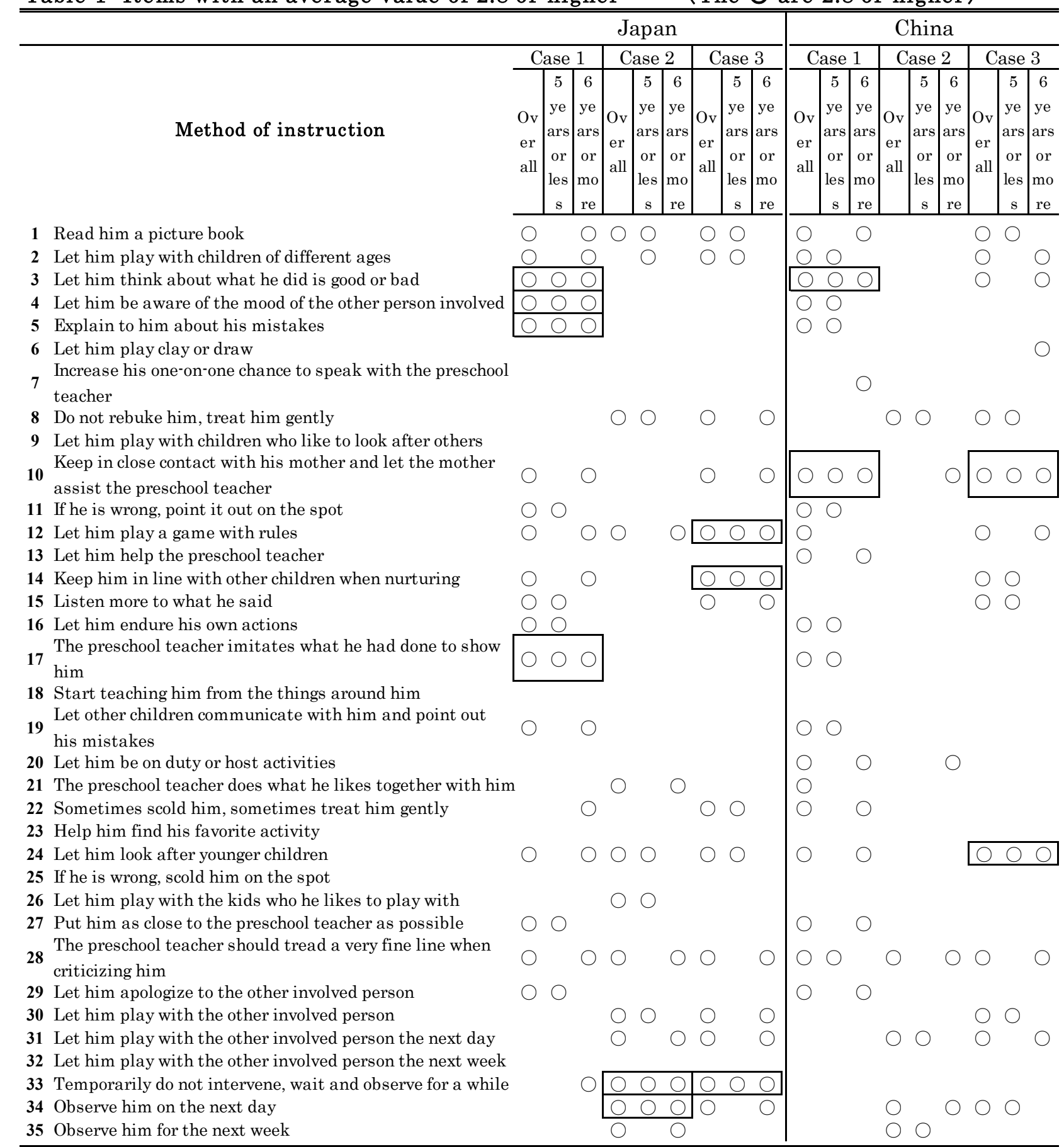

First of all, from table 1 we can find out that, on the whole, no matter in Japan or China, the average value of any item failed to be higher than 2.8 in cases 1,2 , and 3 at the same time, and the average value of most items would vary depending on the amount of childcare experience. From this point, it can be speculated that whether in Japan or China, any single instruction method will not be commonly used in cases 1,2, and 3 at the same time. 
In addition, whether most of the instruction methods will be commonly used or not is related to the childcare experience of the preschool teachers. In other words, this study confirms a correlation between PTT and instruction methods.

Secondly, analyzing from each case, only in case 1 the average score of item 3 is higher than 2.8 for both Japanese and Chinese preschool teachers. It means that when dealing with pretty aggressive children, regardless of the cultural background and how much childcare experience they have, they will all select item 3instructionmethod.

In regards to the difference between Japanese and Chinese preschool teachers, in case 1, item 4 item 5、 and item 17 are the common instruction methods the Japanese preschool teachers use, while Chinese teachers normally select item 10. As for case 2, Japanese preschool teachers usually select methods 33 and 34, whereas there is no common method among Chinese teachers. In case 3, the common instruction methods for Japanese preschool teachers are item 12、item 14 and item33, while for Chinese teachers are item 10 and item24.

Summarizing the above differences, you will find that, in general, Japanese preschool teachers tend to choose the method of 33 'Temporarily do not intervene, wait and observe for a while' more, while Chinese teachers will select more of $10^{\prime} \mathrm{Keep}$ in close contact with his mother and let the mother assist the preschool teacher' method. The reason for this maybe many Chinese parents viewed that preschool was a place where children can have a good start for study (Karasawa, 2006), and they regarded fight or altercation between children as a hindrance to their study and an abnormal phenomenon (Hua, 2004). When their children got involved in fight or altercation, they would ask the preschool teachers about the situation which could influence the action preschool teachers take (Liu, 2013). Therefore, it is easy for preschool teachers to take the intervention of 'Keep in close contact with his mother and let the mother assist the preschool teacher'. In Japan, there are a great number of preschool teachers in kindergarten that let the children solve the problem by themselves (Suizu, 2015; Tomosada, 2009). So, Japanese preschool teachers would apply more of watching over method.

\subsection{Instruction Pattern Classification}

In order to examine the factor structure of the 35 items (instruction methods) used in this study, factor analysis was conducted for each of the three cases in Japan and China respectively. In both analyses, three factors were extracted. All scales showed a sufficient value of $\alpha$ coefficient of 0.75 or more, confirming the reliability. Table 2 and 3 below showed the results.

Based on Table 2, in Japan, names were given to factors extracted from items with a factor loading of 0.35 or more and with common characteristics for three cases, and the contents of the factors were examined. The first factor is from the context that the preschool teachers strive to let the children recognize the bad aspects of their behaviors from items such as 'Let him think about whether what he did was good or bad', 'Let him endure his own actions' and 'Let other children communicate with him and point out his mistakes', which was named as "Promote understanding". The second factor included the intention of the preschool teachers' assistance in items such as 'Keep him in line with other children when nurturing' and 'Let him play a game with rules', and it was named as"Assist playing". Items such as 'Let him play with the other involved person' and 'temporarily do not intervene, wait and observe for a while' containing the viewpoint of the preschool teachers' observation constituted the third factor "Watching over". 
Table 2 Factor analysis (Japan)

\begin{tabular}{|c|c|c|c|c|c|c|c|c|c|}
\hline & \multicolumn{3}{|c|}{ Case 1} & \multicolumn{3}{|c|}{ Case 2} & \multicolumn{3}{|c|}{ Case 3} \\
\hline & $\begin{array}{c}1 \\
1 \\
\text { Promote } \\
\\
\text { underst } \\
\text { anding }\end{array}$ & \begin{tabular}{|l} 
Factor \\
2 \\
Assist \\
\\
playi \\
ng
\end{tabular} & $\mid \begin{array}{c}3 \\
\text { Watc } \\
\text { hing } \\
\\
\text { over }\end{array}$ & $\begin{array}{c}1 \\
1 \\
\text { Promote } \\
\text { underst } \\
\text { anding }\end{array}$ & $\begin{array}{l}\text { Factor } \\
2 \\
\begin{array}{|c|}\text { Assist } \\
\\
\text { playi } \\
\text { ng }\end{array} \mid\end{array}$ & $\mid \begin{array}{c}3 \\
\text { Watc } \\
\text { hing } \\
\\
\text { over }\end{array}$ & $\begin{array}{c}1 \\
1 \\
\text { Promote } \\
\text { underst } \\
\text { anding }\end{array}$ & \begin{tabular}{|c|} 
actor \\
2 \\
Assist \\
\\
playi \\
ng
\end{tabular} & $\begin{array}{c}\text { Watc } \\
\text { hing } \\
\\
\text { over }\end{array}$ \\
\hline 3 Let him think about what he did is good or bad & .643 & -.021 & .136 & .681 & -.013 & .114 & .743 & 011 & -.191 \\
\hline 16 Let him endure his own actions & .598 & .095 & -.123 & .654 & .020 & .095 & .645 & .012 & .022 \\
\hline 4 Let him be aware of the mood of the other person involved & .581 & 146 & .013 & 633 & 164 & .166 & .616 & .016 & .127 \\
\hline $\begin{array}{l}19 \text { Let other children communicate with him and point out his } \\
\text { mistakes }\end{array}$ & .548 & -.136 & .018 & .544 & -.159 & .039 & .531 & -133 & .014 \\
\hline 5 Explain to him about his mistakes & .523 & -.126 & .136 & .446 & .014 & .151 & .515 & .101 & .215 \\
\hline 11 If he is wrong, point it out on the spot & .442 & .116 & -.139 & 441 & .216 & .117 & 482 & 116 & . 012 \\
\hline 17 The preschool teacher imitates what he had done to show him & .362 & -.156 & -.126 & .392 & -.152 & .032 & .362 & -.116 & .103 \\
\hline 29 Let him apologize to the other involved person & .357 & -.126 & -.036 & .284 & .565 & -.006 & .316 & .412 & -.101 \\
\hline 14 Keep him in line with other children when nurturing & .117 & .631 & -.021 & .122 & .631 & 019 & .217 & .723 & .032 \\
\hline 12 Let him play a game with rules & .166 & .593 & .095 & .157 & .593 & .110 & .134 & .668 & .121 \\
\hline $\begin{array}{l}28 \text { The preschool teacher should tread a very fine line when } \\
\text { criticizing him }\end{array}$ & . 072 & .543 & .146 & .071 & .543 & .125 & . 017 & .614 & .112 \\
\hline 2 Let him play with children of different ages & . 057 & .536 & -136 & 206 & .536 & 021 & .121 & .571 & -.119 \\
\hline 24 Let him look after younger children & .142 & 486 & -.126 & .114 & .486 & 011 & .131 & .446 & .012 \\
\hline 1 Read him a picture book & .074 & .472 & .157 & .017 & .472 & 152 & .202 & .431 & .125 \\
\hline 8 Do not rebuke him, treat him gently & .122 & 426 & .152 & .137 & .426 & -.163 & .114 & .362 & -.125 \\
\hline $\begin{array}{l}10 \text { Keep in close contact with his mother and let the mother } \\
\text { assist the preschool teacher }\end{array}$ & 146 & 386 & .191 & 164 & .386 & 131 & .126 & 319 & .331 \\
\hline 22 Sometimes scold him, sometimes treat him gently & -.136 & 364 & .106 & -.156 & .364 & .064 & -.136 & 264 & .464 \\
\hline 30 Let him play with the other involved person & -.171 & 136 & .649 & -.112 & .143[ & .641 & .302 & .114 & .584 \\
\hline 31 Let him play with the other involved person the next day & .122 & -.136 & .625 & .102 & -.156 & .522 & .120 & -.152 & .513 \\
\hline 34 Observe him on the next day & .235 & -.126 & .584 & .024 & -.163 & .512 & -190 & .112 & .451 \\
\hline 33 Temporarily do not intervene, wait and observe for a while & .211 & -.036 & .442 & .116 & 621[ & 317 & .112 & -.016 [ & .372 \\
\hline Eigenvalue & 2.62 & 1.56 & 1.35 & 2.45 & 1.23 & 1.13 & 2.62 & 1.56 & 1.35 \\
\hline Contribution ratio (\%) & 24.9 & 13.2 & 10.3 & 21.3 & 14.2 & 11.3 & 20.6 & 11.2 & 8.2 \\
\hline a coefficient & .93 & .88 & .82 & .92 & .84 & .77 & .83 & .78 & .75 \\
\hline
\end{tabular}

Factors extracted by maximum likelihood method. Items with a coarse frame are the ones with absolute value of the factor load greater than 0.35 . Although the case 2 and case 3 contains a few items with 0.35 or less, the impact on the whole is small, so it is also treated as the analysis object. The below is the same.

From the details of the items that make up each factor, we could conclude that the first factor had the feature that the preschool teachers tended to intervene directly to make the children aware of their behaviors. In contrast, the second factor was characterized by the fact that preschool teachers would like to intervene indirectly without evaluating their behaviors, and the third factor indicated that preschool teachers would choose to treat their behaviors as one type of interaction between the children. 
As seen from Table 3, in China, we also named the items with a factor loading of 0.35 or more for all three

Table 3 Factor analysis (China)

\begin{tabular}{|c|c|c|c|c|c|c|c|c|c|}
\hline & \multicolumn{3}{|c|}{ Case 1} & \multicolumn{3}{|c|}{ Case 2} & \multicolumn{3}{|c|}{ Case 3} \\
\hline & \multicolumn{3}{|c|}{ Factor } & \multicolumn{3}{|c|}{ Factor } & \multicolumn{3}{|c|}{ Factor } \\
\hline & $\begin{array}{c}1 \\
\text { Promote } \\
\text { underst } \\
\text { anding }\end{array}$ & $\begin{array}{c}2 \\
\text { Recti } \\
\text { fy } \\
\text { act }\end{array} \mid$ & $\begin{array}{c}3 \\
\text { Watc } \\
\text { hing } \\
\\
\text { over }\end{array}$ & $\begin{array}{c}1 \\
\text { Promote } \\
\text { underst } \\
\text { anding }\end{array}$ & $\begin{array}{c}2 \\
\text { Recti } \\
\text { fy } \\
\text { act }\end{array} \mid$ & $\begin{array}{c}3 \\
\text { Watc } \\
\text { hing } \\
\\
\text { over }\end{array}$ & $\begin{array}{c}1 \\
\text { Promote } \\
\text { underst } \\
\text { anding }\end{array}$ & $\begin{array}{c}2 \\
\text { Recti } \\
\text { fy } \\
\text { act }\end{array}$ & $\begin{array}{c}3 \\
\text { Watc } \\
\text { hing } \\
\\
\text { over }\end{array}$ \\
\hline 5 Explain to him about his mistakes & .725 & -.013 & .143 & .716 & -.027 & .311 & .685 & .014 & -.119 \\
\hline 16 Let him endure his own actions & .712 & .020 & -.151 & 683 & .095 & .020 & .653 & .020 & .012 \\
\hline 4 Let him be aware of the mood of the other person involved & .685 & .164 & .012 & .621 & .143 & .127 & .616 & .064 & .133 \\
\hline $\begin{array}{l}\text { Keep in close contact with his mother and let the mother } \\
\text { assist the preschool teacher }\end{array}$ & .624 & -.156 & .081 & .541 & .211 & -.126 & .527 & -.129 & .101 \\
\hline 3 Let him think about what he did is good or bad & .618 & -.123 & .164 & .447 & .020 & .215 & .503 & .114 & 1.215 \\
\hline $\begin{array}{l}\text { The preschool teacher imitates what he had done to show } \\
\text { him }\end{array}$ & .546 & .117 & -.131 & .392 & .216 & .166 & .482 & .162 & .021 \\
\hline 11 If he is wrong, point it out on the spot & .436 & -.106 & -.123 & .327 & -.116 & .423 & .307 & -.119 & .510 \\
\hline 20 Let him be on duty or host activities & .012 & .624 & -.017 & .120 & .629 & .013 & .114 & .625 & .013 \\
\hline 13 Let him help the preschool teacher & .127 & .586 & .030 & .122 & .568 & .111 & .212 & .531 & .138 \\
\hline 24 Let him look after younger children & .107 & .513 & .164 & .017 & .543 & .125 & -.167 & .416 & .261 \\
\hline 22 Sometimes scold him, sometimes treat him gently & .073 & .426 & -.156 & .126 & .527 & .021 & .573 & .347 & -.142 \\
\hline 27 Put him as close to the preschool teacher as possible & .017 & .369 & .152 & .022 & .316 & .125 & .621 & .308 & .126 \\
\hline 31 Let him play with the other involved person the next day & .264 & .143 & .608 & -.101 & .131[ & .671 & 1.302 & .211 & .636 \\
\hline 33 Temporarily do not intervene, wait and observe for a while & .122 & -.156 & .593 & .210 & -.159 & .581 & .012 & -.115 & .607 \\
\hline 30 Let him play with the other involved person & -.162 & .063 & .512 & .226 & .027 & .472 & .071 & -.212 & .577 \\
\hline 34 Observe him on the next day & .112 & -.123 & .484 & .102 & -.125 & .367 & -.110 & .168 & .459 \\
\hline 35 Observe him for the next week & .271 & -.104 & .413 & .416 & .116 & .328 & .221 & -.012 & .392 \\
\hline Eigenvalue & 2.172 & 1.325 & 1.235 & 2.325 & 1.276 & 1.125 & 2.025 & 1.256 & 1.035 \\
\hline Contribution ratio (\%) & 22.9 & 12.7 & 10.1 & 20.3 & 12.2 & 9.3 & 18.6 & 11.2 & 8.7 \\
\hline a coefficient & .94 & .91 & .88 & .89 & .82 & .78 & .87 & .81 & .76 \\
\hline
\end{tabular}

casesand discussed the contents of the factors. From the contents constituting the factors, the first and third factor in China were almost the same as those in Japan, thus the first factor in China was also named as "Promote understanding" and the third factor "Watching over". The second factor contained the movement that the preschool teachers would replace their behaviors with other childcare activities such as items 'Let him be on duty or host activities', 'Let him look after younger children' and 'Let him help the preschool teacher', so it was named as "Rectify act". Same as in Japan, compared to the first and third factor, the second factor shared a feature that the preschool teachers tended to intervene indirectly without evaluating their behaviors. On the other hand, from the contents of the items that constitute the second factor, unlike "Assist playing" in Japan which included the intention of leading the children from their behaviors to other games, the factor "Rectify act" for the preschool teachers in China was with minor punishment against the children who caused the problem.

\subsection{Differences in instruction patterns by case and experience}


In this section, by comparing the average value of each instruction pattern, the characteristics of the patterns in each Table 4 Average values of each pattern (Analysis of variance and Tukey method)

\begin{tabular}{|c|c|c|c|c|c|c|c|c|c|c|c|c|c|}
\hline & & & Jap & & & & & & & Chi & & & \\
\hline & Case & Overal & & $\begin{array}{c}5 \text { years } \\
\text { or less }\end{array}$ & $\begin{array}{l}6 \text { years } \\
\text { or more }\end{array}$ & Tukey & & Case & Overall & & $\begin{array}{c}5 \text { years } \\
\text { or less }\end{array}$ & $\begin{array}{l}6 \text { years } \\
\text { or more }\end{array}$ & Tukey \\
\hline & 1 & 3.24 & $\mathrm{M}$ & 3.31 & 3.17 & N.S. & & 1 & 3.18 & M & 3.36 & 2.64 & $6<5$ \\
\hline Factor 1 & & & SD & 0.36 & 0.28 & & & & & & & & \\
\hline Promote & 2 & 2.62 & $\mathrm{M}$ & $\begin{array}{l}2.65 \\
0.27\end{array}$ & $\begin{array}{l}2.59 \\
028\end{array}$ & N.S. & Promote & 2 & 2.56 & M & 2.55 & 2.59 & N.S. \\
\hline understa & & & M & 2.65 & 2.49 & & understan & & & $\mathrm{M}$ & 278 & 272 & \\
\hline nding & 3 & 2.57 & $\mathrm{SD}$ & 0.32 & 0.23 & N.S. & ding & 3 & 2.77 & $\mathrm{SD}$ & 0.22 & 0.26 & N.S. \\
\hline & & $\mathrm{Tul}$ & & $2,3<1$ & $3,2<1$ & & & & Tuk & & $2,3<1$ & N.S. & \\
\hline & 1 & 273 & M & 2.51 & 2.97 & $5<6$ & & 1 & 271 & $\mathbf{M}$ & 2.64 & 2.92 & $5<6$ \\
\hline & 1 & 2.15 & SD & 0.26 & 0.32 & J & & 1 & 2.1 & SD & 0.27 & 0.28 & \\
\hline Factor 2 & 2 & 289 & M & 2.91 & 2.87 & NS & & 2 & 262 & M & 2.59 & 2.71 & NS \\
\hline Assist & & & SD & 0.31 & 0.26 & & actor 2 & & 2.02 & SD & 0.31 & 0.26 & \\
\hline playing & 3 & 316 & M & 3.14 & 3.18 & NS & & 3 & 27 & M & 2.69 & 2.78 & NS \\
\hline & & 5.10 & SD & 0.31 & 0.29 & & & & & $\mathrm{SD}$ & 0.25 & 0.36 & \\
\hline & & $\mathrm{Tul}$ & & $1<2<3$ & $2,1<3$ & & & & Tuk & & N.S. & $2<1$ & \\
\hline & 1 & 255 & $\mathrm{M}$ & 2.50 & 2.59 & NS & & 1 & 267 & M & 2.73 & 2.65 & NS \\
\hline & 1 & 2.53 & SD & 0.24 & 0.27 & N.S. & & 1 & 2.07 & $\mathrm{SD}$ & 0.19 & 0.26 & N.S. \\
\hline Factor 3 & 2 & 328 & M & 3.22 & 3.34 & NS & Factor 3 & 2 & 276 & M & 2.75 & 2.78 & NS \\
\hline Watching & & & SD & 0.33 & 0.32 & & Watching & & & SD & 0.24 & 0.26 & N. \\
\hline over & 3 & 335 & M & 3.31 & 3.39 & NS & over & 3 & 270 & M & 2.61 & 2.73 & NS \\
\hline & & & SD & 0.34 & 0.41 & & & & 2.10 & SD & 0.25 & 0.28 & N.S. \\
\hline & & $\mathrm{Tul}$ & & $1<2,3$ & $1<2,3$ & & & & Tuk & & N.S. & N.S. & \\
\hline
\end{tabular}

N.S.: Not significant, 1: Case 1, 2: Case 2, 3: Case 3, 5:5 years or less, $6: 6$ years or more. $\quad 2,3<1$ : There is no statistical significance between "Case 2" and "Case 3", but "Case 1" has significant difference from them and the average is higher than them.

case were clarified. Moreover, toward three cases of problem children, how Japanese and Chinese preschool teachers selecting the patterns was revealed.

As shown in Table 4, by Analysis of variance of two variables (case 1, case 2, case $3 \times 5$ years or less, 6 years or more), in Japan, for factor 1 , the main effects $(\mathrm{F}(2,683)=12.86, \mathrm{p}<.01)$ by case are meaningful. Therefore, we conducted multiple comparison by Tukey method for the three cases, and the result showed the average value (3.24) of case 1 is higher than other two cases. This is implying that in case1, preschool teachers would apply "Promote understanding "instruction pattern more. As to factor 2 , the interaction effect of case and experience $(\mathrm{F}(4,6283)=$ $19.32, \mathrm{p}<.01)$, both of the main effects for the $\operatorname{cases}(\mathrm{F}(3,178)=13.41, \mathrm{p}<.01)$, and experience $(\mathrm{F}(1,227)=4.05$, $\mathrm{p}<.05)$ are meaningful. After that, we also conducted multiple comparison which showed case 3 had the highest average value (3.16). Moreover, in case 1, the average value of the preschool teachers who have more than 6 years' experience (2.97) is higher than those with less than 5 years' experience (2.51).This can explain that "Assist playing "instruction pattern would be normally applied in case 3 but also be used in case 1 by the preschool teachers who have more than 6 years' experience. With regards to factor3, the main effects $(F(1,962)=10.23, p<.01)$ by case are meaningful. Multiple comparisons illustrated that average value of case $2 \& 3(3.28,3.35)$ is higher than case 1 . This is suggesting that in case $2 \& 3$, the instruction pattern of "Watching over" is more commonly used.

While for Chinese preschool teachers, regarding factor 1 , the case and experience interaction effect $(\mathrm{F}(2,1297)=$ $14.75, \mathrm{p}<.01)$ is significant. From the Multiple comparison results, in case 1, the average value of the preschool teachers who have more than 6 years' experience (2.64) is lower than those with less than 5 years' experience (3.36). This indicates that preschool teachers with less than 5 years' experience use "Promote understanding "more for case 1 situation. For factor 2 , the case and experience interaction effect $(F(1,8022)=10.26, p<.01)$ is significant. Multiple comparison result displays that, in case 1, the average value of the preschool teachers with more than 6 years' experience (2.92) is higher than those with less than 5 years' experience (2.64). From this we can find out that, the preschool teachers with more than 6 years' experience will often apply "Rectify act "instruction pattern in case 1 .

Summarizing the above results, we can conclude that the biggest difference between Japanese and Chinese preschool teachers is in Case 1. With the average of 2.8 as the dividing line, with the increase of childcare experience, the average value of factor 2 of Japanese preschool teachers will rise while the average value of factor 8 
1 of Chinese teachers will decrease, and that of factor 2 will increase. It is implying that dealing with problem children who are quite aggressive, as the years of preschool teacher experience grow, Japanese preschool teachers chose a flexible involvement which combined "Promote understanding" with "Assist playing" depending on the circumstance. However, Chinese preschool teachers tend to use 'Rectify act' more instead of the pattern of "Promote understanding'.

\section{Discussion}

Finally, based on the results of this study, I would like to conclude a comprehensive discussion on the characteristics of Japanese and Chinese preschool teachers 'instruction patterns in Concrete Cases.

The main characteristic of Japanese preschool teachers 'instruction patterns was "Assist playing" which included the intention of leading the child from their behaviors to other games, whereas Chinese teachers was "Rectify act" which was with minor disciplinary action against the child who caused the problem. Such difference is considered to be strongly related to the preschool teachers' awareness of fight or altercation between children. The Ministry of Education of Japan (2018) stated its standpoint that "Toddlers can feel the mood of their friend bit by bit and sprout patience through playing such as fight". In other words, in Japan, fights or altercations are indispensable for the development of infants, and Japanese preschool teachers perform more "Assist playing” to protect children's passion for playing. In China, on the other hand, many preschool teachers think that fights or altercations between children are bad behaviors, and those who caused fights are regarded as problem children (Xu, 2016). Therefore, it is suggested that Chinese preschool teachers try to isolate the children from fight through "Rectify act".

Additionally, dealing with problem children who were quite aggressive, as the years of preschool teacher experience grow, Japanese preschool teachers choose a flexible involvement which combined "Promote understanding" with "Assist playing" depending on the circumstance. However, Chinese preschool teachers tend to use "Rectify act" more instead of the pattern of "Promote understanding". The following points can be presented as reasons. In China, disciplinary actions help improve children's behavioral cognition (Hua, 2004). However, due to the lack of trust from parents, inexperienced preschool teachers were rather conservative of daily care in order to avoid conflict with their parents (Wang, 2015), thereby they are afraid to apply "Rectify act" method. But along with experience growth, they start to use 'Rectify act' instead of 'Promote understanding' after gaining trust from parents.

\section{References}

Dong, C. \&Hongo, K. (2009). The cross-cultural comparison of development of self-regulation in interpersonal situations between Japanese and Chinese young children. Annual Report Graduate School of Education, Tohoku University. Vol. 57(2), pp.203-218.

Hua, X. (2004). Survey on parents'perceptions of children's conflicts among 3-year-olds. Studies in Preschool Education. Vol. 6, pp.5-7.

Kajita, M., Sugimura, H., Kiriyama, M., Goto, M. \& Yoshida, N. (1988). How Does a Caretaker Approach Concrete Cases of Problem Child? Bulletin of the Faculty of Education. The Department of Educational Psychology. Vol. 35, pp.111-136.

Kanamori, Y. (2017). A Study about the Children's Human Relations in the Bugs Catch at the Kindergarten. Bulletin of Faculty of Early Childhood Care and Education Ohka gakuen University. Vol. 16, pp.161-175.

Karasawa, M., Hayashi, A. \&Mathumoto, T. (2006). Cultural Meaning of Early Childhood Education - Intracultural and Intercultural Comparisons Among three cultures, Japan, the United States, and China -. Center of Developmental Education and Research. Vol. 20, pp.33-42.

Liu, H. \&Kuramothi, K. (2008). Chinese child-care workers' perceptions about peer conflict among early children: in comparison with Japanese child-care workers' perceptions. The Japanese journal of infant care and early childhood education. Vol. 17, pp.63-72.

Liu, H. \&Kuramothi, K. (2013). Urban and rural Chinese child-care workers' perceptions about peer conflict. Tokyo Gakugei University Journal. Vol. 64(2), pp.211-219. 
Ministry of Education of Japan. (2018). The AREA related to Relationship with people "Human relations". Kindergarten teaching procedures, $\mathrm{p} 77$.

Shiraishi, T., Tomosada, K., Irie, R. \&Ohara, T. (2007). How do kindergarten teachers cope with children's conflicts? Analysis of student teacher's reports. Academic bulletin, Faculty of Education, Yamaguchi University. Vol. 57, pp.287-299.

Suizu, S. \&Mathumoto, H. (2015). Kindergarten Teacher Interventions in Peer Conflict among Young Children: with a Focus on the Role of 'Nagomase' Interventions. Research on early childhood care and education in Japan. Vol. 53(3), pp.273-283.

Tobin, J., Hsueh, Y. \&Karasawa, M.(2011). Preschool in Three Cultures Revisited. University of Chicago Press, pp.109-125.

Tobin, J., Wu, D. \& Davidson, D. (1989). Preschool in Three Cultures. New Haven: Yale University Press, pp.116-132.

Tomosada, K. (2009). Childcare professionals in supporting with children's conflicts in kindergarten. Academic bulletin, Faculty of Education, Yamaguchi University. Vol. 59, pp.239-251.

Wang, Y. (2015). Strategies to improve communication between new teachers and parents in kindergartens. Modern Preschool Education. Vol. 10, pp.58-62.

$\mathrm{Xu}$, Y. (2016). Cross-cultural comparison of Preschool teachers' management methods to trouble between China and Japan. Modern Education Science. Vol. 5, pp.152-155.

Yang, J. (2012). Different views on education between Japan and China: from a point of view "Being parents of an egg”. Annual Report Graduate School of Humanities and Sciences, Nara Women's University. Vol. 28, pp.145-155. 